\title{
Growth of a bonelike apatite on chitosan microparticles after a calcium silicate treatment
}

\author{
I.B. Leonor ${ }^{\mathrm{a}, \mathrm{b}, *}$, E.T. Baran ${ }^{\mathrm{a}, \mathrm{b}}$, M. Kawashita ${ }^{\mathrm{c}}$, R.L. Reis ${ }^{\mathrm{a}, \mathrm{b}}$, T. Kokubo ${ }^{\mathrm{d}}$, T. Nakamura ${ }^{\mathrm{e}}$ \\ a 3B's Research Group, Department of Polymer Engineering, University of Minho, Campus de Gualtar, 4710-057 Braga, Portugal \\ ${ }^{\mathrm{b}}$ Institute for Biotechnology and Bioengineering (IBB), PT Government Associated Laboratory, Braga, Portugal \\ ${ }^{\mathrm{c}}$ Center for Research and Strategy Support, Tohoku University, Aramaki-Aoba, Aoba-ku, Sendai 980-8579, Japan \\ ${ }^{\mathrm{d}}$ Department of Biomedical Sciences, College of Life and Health Sciences, Chubu University, 1200 Matsumoto Kasugai, Aichi 487-8501, Japan \\ ${ }^{\mathrm{e}}$ Department of Orthopaedic Surgery, Faculty of Medicine, Kyoto University, Sakyo-ku, Kyoto 606-8506, Japan
}

Received 27 September 2007; received in revised form 29 January 2008; accepted 6 March 2008

Available online 20 March 2008

\begin{abstract}
Bioactive chitosan microparticles can be prepared successfully by treating them with a calcium silicate solution and then subsequently soaking them in simulated body fluid (SBF). Such a combination enables the development of bioactive microparticles that can be used for several applications in the medical field, including injectable biomaterial systems and tissue engineering carrier systems. Chitosan microparticles, $0.6 \mu \mathrm{m}$ in average size, were soaked either for $12 \mathrm{~h}$ in fresh calcium silicate solution (condition I) or for $1 \mathrm{~h}$ in calcium silicate solution that had been aged for $24 \mathrm{~h}$ before use (condition II). Afterwards, they were dried in air at $60{ }^{\circ} \mathrm{C}$ for $24 \mathrm{~h}$. The samples were then soaked in SBF for 1, 3 and 7 days. After the condition I calcium silicate treatment and the subsequent soaking in SBF, the microparticles formed a dense apatite layer after only 7 days of immersion, which is believed to be due to the formation of silanol ( $\mathrm{Si}-$ $\mathrm{OH}$ ) groups effective for apatite formation. For condition II, the microparticles successfully formed an apatite layer on their surfaces in SBF within only 1 day of immersion.
\end{abstract}

(C) 2008 Acta Materialia Inc. Published by Elsevier Ltd. All rights reserved.

Keywords: Apatite; Biomimetic process; Calcium silicate; Chitosan; Microparticles

\section{Introduction}

Organic materials have surfaces which can be tailored to achieve different properties, such as hydrophilicity and the capability of carrying functional groups. In addition, they have a high degree of structural flexibility and may have strong surface-specific binding forces, such as the ability of their functional groups to chelate metal ions [1]. Therefore, new strategies aim at the surface modification of organic materials to obtain a biologically active surface while maintaining their bulk properties. A prime example

\footnotetext{
* Corresponding author. Address: 3B's Research Group, Department of Polymer Engineering, University of Minho, Campus de Gualtar, 4710-057 Braga, Portugal. Tel.: +351 253604498.

E-mail address: belinha@dep.uminho.pt (I.B. Leonor).
}

of biomineralization would be a polymer matrix which can be placed into a metastable solution and induce precipitation to occur within the polymer but not in the solution [1]. For instance, the use of degradable polymers as matrices is a major approach in the development of materials for bone regeneration and replacement. However, biodegradable materials have to degrade without an unresolved inflammatory response or an extreme immunogenicity or cytotoxicity [2-4].

Chitosan, a linear polysaccharide, composed of glucosamine and $N$-acetyl glucosamine linked in a $\beta(1-4)$ manner, is one of the most abundant natural polysaccharides, obtained from chitin by deacetylation [5-7]. The high content of primary amino groups gives chitosan unique properties, and in addition it is non-toxic, biocompatible and degradable, which makes it very attractive for clinical uses 
[5-10]. It also has good solubility in different organic acid solutions and sufficient resistance in alkaline solutions [11].

Synthetic biomaterials for tissue regeneration or replacement have to show physical and/or biological functions in intimate contact with hard or soft living tissue, but they are generally non-vital and bond poorly with the host tissue [12]. Therefore, the interface between the tissue and the implants is not strong, and the interface detaches easily under shear and distraction loads [13].

The biological responses of materials, such as bone bonding, are very important in clinical applications such as bone repair. For example, hydroxyapatite (HA), one of the major constituents of bones and teeth $[4,14,15]$, has often been designated as an osteointegrating and/or osteoconductive (i.e. bioactive) material [16]. Bioactive HA ceramic in various forms has been used clinically during the last few decades because of its good biocompatibility $[4,14,15]$ and efficacy in promoting biointegration for implants in both hard and soft tissue [17]. Moreover, the analysis of the interface between the bone and the bioactive implant is morphologically comparable to that of cement lines found naturally in bone remodelling sites, and this interfacial layer is formed on the chemically active surface of the biomaterial, which is one of the key features of the bonding zone and is unique to bioactive materials $[18,19]$. Such a type of calcium phosphate $(\mathrm{Ca}-\mathrm{P})$ layer is not observed around materials that are not bioactive, like metals and polymers, when used in bone defects, implying that the surface biomineralization of the bone mineral-like $\mathrm{Ca}-$ $\mathrm{P}$ is a precondition of bioactivity [12]. Furthermore, for bone replacement, a strong bonding between the host bone and the osteoconductive surface is also required [20-23]. Chitosan itself is not able to induce the formation of an apatite layer, i.e. it lacks bioactivity, even though it contains amino and hydroxyl groups.

Bioactivity can be induced on bioinert surfaces either by the formation of functional groups or by the formation of thin ceramic phases that have the potential to form functional groups on exposure to a body environment [24]. The key point lies in the design of a surface that is organized and functionalized so as to control the mechanisms of heterogeneous nucleation.

For instance, it has been demonstrated [25] that by using a simple biomimetic spraying methodology on chitosan fibre meshes, scaffolds, produced by wet-spinning, were able to induce the formation of a $\mathrm{Ca}-\mathrm{P}$ layer when immersed in a simulated body fluid.

It has been reported that silanol $(\mathrm{Si}-\mathrm{OH})$ groups on polymeric materials can induce apatite formation in acellular simulated body fluids (SBF) with ion concentrations nearly identical to those of human blood plasma [26-29]. The incorporation of $\mathrm{Si}-\mathrm{OH}$ groups into the chitosan microparticles can give bone-bonding ability to the microparticles, accelerating the tissue integration, which leads to the unique strength of such interfaces. In addition, their degradation rates make this material suitable as a bone substitute. Furthermore, chitosan microparticles can be easily handled during surgery, and such a mouldable visco-elastic material or injectable bone substitute is more easily applied than pure HA powder or granules and avoids the migration of HA particles [11,18,30-32].

The aim of this study was to incorporate $\mathrm{Si}-\mathrm{OH}$ groups onto chitosan microparticles by soaking them in a calcium silicate solution, in order to obtain bioactive microparticles for designing an injectable bone substitute system.

\section{Materials and methods}

Chitosan (with a deacetylation degree of $87 \%$ ) was obtained from Sigma Chemical Co. (St. Louis, MO). Acetic acid and cyclohexane were obtained from Merck (Darmstadt, Germany). Sodium sulphate was obtained from Aldrich Chemical Co. (Milwaukee, WI). All the other chemicals used were of analytical grade.

\subsection{Preparation of chitosan microparticles}

Chitosan microparticles were prepared by the water-inoil/solvent evaporation method [33]. A $50 \mathrm{ml}$ quantity of chitosan solution $(0.25 \%(\mathrm{w} / \mathrm{v})$, in $1 \%$ aqueous acetic acid) containing Tween- $80(0.5 \mathrm{ml})$ was prepared by using cyclohexane $(75 \mathrm{ml})$ as the organic phase. Aqueous chitosan solution was emulsified with cyclohexane in a glass beaker $(250 \mathrm{ml})$ by magnetic mixing at $1100 \mathrm{rpm}$ until the formation of a milky solution (about $30 \mathrm{~min}$ ). The stabilization of the chitosan droplets in the emulsion was achieved by ionic crosslinking of chitosan with sodium sulphate [33]. A sodium sulphate solution $(10 \%, 5 \mathrm{ml})$ was added to the suspension in a dropwise manner. The amount of sodium sulphate needed for stabilization of chitosan microparticles was estimated visually by premixing sodium sulphate solution with chitosan solution without cyclohexane. The volume of sodium sulphate at which turbidity began was regarded as the ideal amount. Afterwards, the suspension was further stirred on a magnetic stirrer for $2 \mathrm{~h}$ at room temperature. Cyclohexane was removed from the emulsion by using either rotary evaporation or slow magnetic mixing of the suspension overnight. The chitosan particles formed were washed by centrifuging the suspension at $8000 \mathrm{rpm}$ for 25 min using a clinical centrifuge. The microparticle pellet was resuspended with distilled water and centrifuged again. This procedure was repeated four times in order to wash the chitosan particles free from the emulsifying agent and excess sodium sulphate used in their preparation.

\subsection{Calcium silicate solution treatment}

In this study, the chitosan microparticles were freezedried to remove the water content before the calcium silicate solution treatment. Tetraethoxysilane (TEOS: $\left.\mathrm{Si}\left(\mathrm{OC}_{2} \mathrm{H}_{5}\right)_{4}\right)($ Nacalai Tesque Inc., Japan), ultrapure water, ethyl alcohol $\left(\mathrm{C}_{2} \mathrm{H}_{5} \mathrm{OH}\right)$ (Nacalai Tesque Inc., Japan), $1.0 \mathrm{M}$ aqueous $\mathrm{HCl}$ solution and calcium chloride $\left(\mathrm{CaCl}_{2}\right)$ (Nacalai Tesque Inc., Japan) were mixed for $10 \mathrm{~min}$ at $0{ }^{\circ} \mathrm{C}$ 
in order to prepare a calcium silicate solution with a molar ratio of $\mathrm{TEOS} / \mathrm{H}_{2} \mathrm{O} / \mathrm{C}_{2} \mathrm{H}_{5} \mathrm{OH} / \mathrm{HCl} / \mathrm{CaCl}_{2}$ of $1.0 / 4.0 / 4.0$ / $0.014 / 0.20$. The freeze-dried microspheres were immediately soaked in $10 \mathrm{ml}$ of calcium silicate solution at $36.5^{\circ} \mathrm{C}$ and $120 \mathrm{rpm}$ under two conditions: condition I, for $12 \mathrm{~h}$ in fresh solution; and condition II, for $1 \mathrm{~h}$ in the same amount of calcium silicate solution that has been aged for $24 \mathrm{~h}$ before use. The flasks were then placed in a shaker incubator at 120 strokes $\min ^{-1}$. The specimens were filtered and then dried in air at $60^{\circ} \mathrm{C}$ for $24 \mathrm{~h}$.

\subsection{Soaking in $S B F$}

The obtained specimens were soaked in $20 \mathrm{ml}$ of SBF [26] with ion concentrations $\left(\mathrm{Na}^{+} 142.0, \mathrm{~K}^{+} 5.0, \mathrm{Ca}^{2+}\right.$ $2.5, \mathrm{Mg}^{2+} 1.5, \mathrm{Cl}^{-} 147.8, \mathrm{HCO}_{3}^{-} 4.2, \mathrm{HPO}_{4}^{2-} 1.0, \mathrm{SO}_{4}^{2-}$ $0.5 \mathrm{mM}$ ) nearly identical to those of human blood plasma in $70 \mathrm{ml}$ polystyrene sterile flasks at $36.5^{\circ} \mathrm{C}$ for different periods up to 7 days. The SBF was prepared by dissolving reagent-grade $\mathrm{NaCl}, \mathrm{NaHCO}_{3}, \mathrm{KCl}, \mathrm{K}_{2} \mathrm{PO}_{4} \cdot 3 \mathrm{H}_{2} \mathrm{O}$, $\mathrm{MgCl}_{2} \cdot 6 \mathrm{H}_{2} \mathrm{O}, \mathrm{CaCl}_{2}$ and $\mathrm{NaSO}_{4}$ (Nacalai Tesque Inc., Japan) in distilled water, buffered at $\mathrm{pH} 7.40$ with trishydroxymethylaminomethane $\left(\left(\mathrm{CH}_{2} \mathrm{OH}\right)_{3} \mathrm{CNH}_{3}\right)($ Nacalai Tesque Inc., Japan) and $1 \mathrm{M}$ hydrochloric acid (Nacalai Tesque Inc., Japan) at $36.5^{\circ} \mathrm{C}$. The flasks were put in an incubator shacked at 120 strokes $\mathrm{min}^{-1}$. After soaking, the specimens were removed from the SBF, washed with distilled water and dried.

\subsection{Analyses of surface and SBF}

The surfaces of polymeric microparticles before and after the solution treatments and the subsequent soaking in SBF were analysed by the following techniques:

(i) Fourier transform attenuated total reflectance infrared spectroscopy (FTIR; Magna 860, Nicolet Co., USA) was used to analyse the chemical structure of the polymeric microparticles before and after soaking in the calcium silicate solution, as well as after immersion in SBF (results were compared to non-immersed controls). All spectra were recorded using at least 64 scans and $2 \mathrm{~cm}^{-1}$ resolution, in the spectral range $4000-600 \mathrm{~cm}^{-1}$.

(ii) X-ray photoelectron spectroscopy (XPS) was performed on a VG ESCALAB 250iXL spectrometer. Pressure in the analysis chamber was around $8 \times 10^{-10}$ mbar. Neutralization of the surface charge was performed by using both a low-energy flood gun (electrons in the range $0-14 \mathrm{eV}$ ) and an electrically grounded stainless steel screen placed directly on the sample surface. The XPS measurements were carried out using monochromatic $\mathrm{Al} \mathrm{K} \alpha$ radiation $(h v=1486.92 \mathrm{eV})$. Photoelectrons were collected from a take-off angle of $90^{\circ}$ relative to the sample surface. The measurement was done in constant analyser energy mode (CAE), with $100 \mathrm{eV}$ for survey spectra and $20 \mathrm{eV}$ for high-resolution spectra. Charge referencing was done by setting the lower binding energy $\mathrm{C}$ 1s photopeak at $285.0 \mathrm{eV}$ from the surface contamination (adventitious carbon).

(iii) Thin-film X-ray diffraction (TF-XRD; RINT2500, Rigaku Co., Japan) was used to identify any crystalline phase present on the polymeric microparticles after soaking in the calcium silicate solution as well as after immersion in SBF (results were compared to non-immersed controls), and to characterize the crystalline/amorphous nature of the apatite films. The data collection was performed by the $2 \theta$ scan method, with $1^{\circ}$ as the incident beam angle using a $\mathrm{Cu} \mathrm{K} \alpha \mathrm{X}$-ray line and a scan speed of $0.05^{\circ} \mathrm{min}^{-1}$ in $2 \theta$.

(iv) Field-emission scanning electron microscopy (FESEM: S-4700, Hitachi Ltd., Japan) coupled to energy-dispersive electron X-ray spectroscopy (EDS: EMAX-7000, Horiba Ltd., Japan) was used to observe the morphology of the polymeric microparticles and to detect the calcium, phosphorous and silicon elements on the coating surface before and after soaking in the calcium silicate solution and after the subsequent soaking in $\mathrm{SBF}$, for the different experimental conditions and controls. Prior to EDS and SEM analysis, sample surfaces were carbon coated (Fisons Instruments, Evaporation PSU CA508, UK) and gold sputtered (Fisons Instruments, Sputter Coater SC502, UK), respectively.

\subsection{Solution analysis}

Element concentrations of the SBF, before and after soaking the polymeric microparticles, were measured using inductively coupled plasma atomic emission spectrometry (ICP; SPS-1500VR, Seiko Instruments Inc., Japan).

\section{Results}

\subsection{Surface structural changes of the microparticles after the calcium silicate treatment}

Fig. 1 shows FE-SEM photograph of as-prepared chitosan microparticles. The average size of chitosan microparticles was found to be $0.6 \mu \mathrm{m}$. Fig. 2 shows an FE-SEM photograph of freeze-dried chitosan microparticles. Freeze-drying caused the chitosan microparticles to lose their spherical morphology, with elongated thread-like structures being produced. Similarly, the size and morphology of freeze-dried polycaprolactone nanoparticles were found to have changed from the original spherical shape because of aggregation and cake formation after freezedrying [34]. The effect of freeze-drying on hydrogel microparticles can be even more pronounced. Similar to our results obtained with chitosan microparticles, typical SEM images of gelatin microparticles, which were 


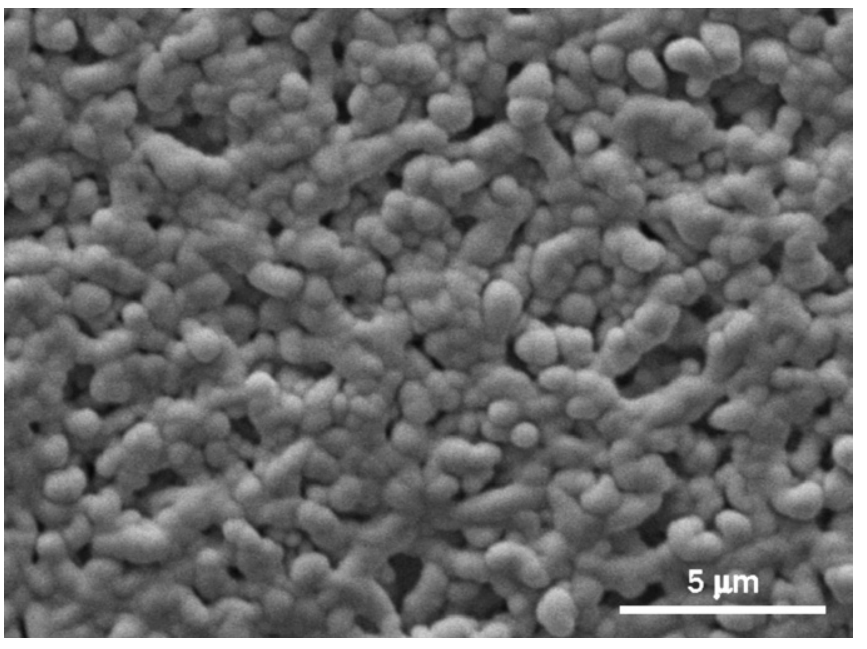

Fig. 1. SEM micrographs of the surface of prepared chitosan microparticles.

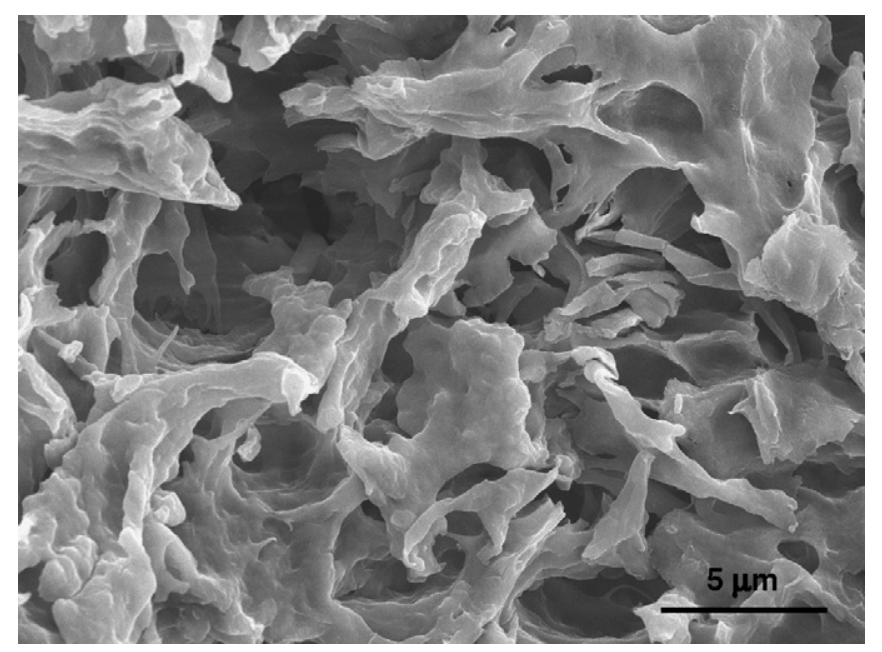

Fig. 2. SEM microphotographs of the surface of chitosan microparticles after freeze-drying.

originally spherical, were observed to be irregularly shaped string-like aggregates containing spherical domains after freeze-drying, as shown in Fig. 1 [35].

Fig. 3 shows FTIR spectra of the surface of microparticles subjected to the calcium silicate treatment under condition I or II.

Before the calcium silicate treatment, two main reflection peaks of chitosan were observed, at 1620 and $1524 \mathrm{~cm}^{-1}$, which were ascribed to amide I and amide II, respectively. After the calcium silicate treatment under both conditions, new reflection peaks of silanol $(\mathrm{Si}-\mathrm{OH})$ groups and siloxane $(\mathrm{Si}-\mathrm{O}-\mathrm{Si})$ groups were observed. Reflection peaks of $\mathrm{Si}-\mathrm{OH}$ groups are typically observed for silica gels [36]. Condition II gave higher intensities of the $\mathrm{Si}-\mathrm{O}-\mathrm{Si}$ peak at $\sim 1089 \mathrm{~cm}^{-1}$ than did condition I. This can be attributed to the better polycondensation of TEOS in the calcium silicate solution under condition II than under condition I. The bands at $\sim 3673$ and $\sim 2979 \mathrm{~cm}^{-1}$ can be attributed to the hydroxyl $(-\mathrm{OH})$ groups present in the structure of chitosan [36,37], while the bands which lie in the range $3680-3075 \mathrm{~cm}^{-1}$ can be ascribed to the $\mathrm{OH}$ groups after the calcium silicate treatment, indicating that TEOS was completely hydrolysed into $\mathrm{Si}-\mathrm{OH}$ groups [36]. Additionally, the reflection peaks of amide I and amide II were still observed even after the calcium silicate treatment.

Table 1 shows the atomic concentrations, calculated from XPS spectra, and the corresponding atomic values for chitosan microparticles, before and after calcium silicate treatment under condition I or II.

The XPS peak ratios show progressive disappearance of the underlying substrate signals $\left(\mathrm{C}_{1 \mathrm{~s}}\right.$ and $\left.\mathrm{N}_{1 \mathrm{~s}}\right)$ and the appearance of peaks of $\mathrm{Si}_{2 p}$ and $\mathrm{Ca}_{2 p}$ for conditions I and II (Table 1). In addition, there is a clear increase in oxygen content after the calcium silicate treatment. For condition II, the increase in silicon content was higher than for condition I.

Upon calcium silicate treatment, the relative $\mathrm{C} / \mathrm{Si}$ ratio of the chitosan microparticles was 1.7 and 1.6 for conditions I and II, respectively.

\subsection{Surface structural changes of the microparticles in $S B F$}

After soaking in SBF, FTIR analysis was performed in order to characterize the chemical structure of the obtained calcium phosphate under the different conditions. Fig. 4 shows the FTIR spectra of the surface of microparticles subjected to the calcium silicate treatment under condition I or II and subsequently soaked in SBF up to 7 days.

After soaking in SBF for 1 day, reflection peaks of the phosphate group $\left(\mathrm{PO}_{4}^{3-}\right.$ ) (around 1028 and $1012 \mathrm{~cm}^{-1}$ ) were observed for both conditions. However, comparing both spectra, it was noted that the intensity of this peak under condition II was strong and appeared along with a well-defined band at $1012 \mathrm{~cm}^{-1}$ (see Fig. 4b) [38]. As the soaking time in SBF increases, the phosphate band becomes sharper.

Fig. 5 shows TF-XRD patterns of the surfaces of chitosan microparticle treated with a calcium silicate solution under condition I or II and subsequently soaked in SBF up to 7 days.

Calcium sulphate $\left(\mathrm{CaSO}_{4} \cdot 0.5 \mathrm{H}_{2} \mathrm{O}\right.$, ASTM JCPDS 45 0848) was partially formed on the surface of the chitosan microparticles after the calcium silicate treatment under both conditions I and II. The TF-XRD patterns of the surface of chitosan microparticles treated with a calcium silicate solution under condition II exhibit two broad diffraction peaks, which, from their positions and intensities, can be assigned to an apatite-like phase (ASTM JCPDS 9-432) after soaking in SBF for only 1 day (see Fig. $5 b$ ), whereas that treated with a calcium silicate under condition I showed them after soaking in SBF for 7 days (see Fig. 5a). The peaks at $25.87^{\circ}$ and $31.78^{\circ}$ in $2 \theta$ corresponded to (002) and (211) diffraction planes of apatite, respectively. With further soaking time in SBF, new diffrac- 


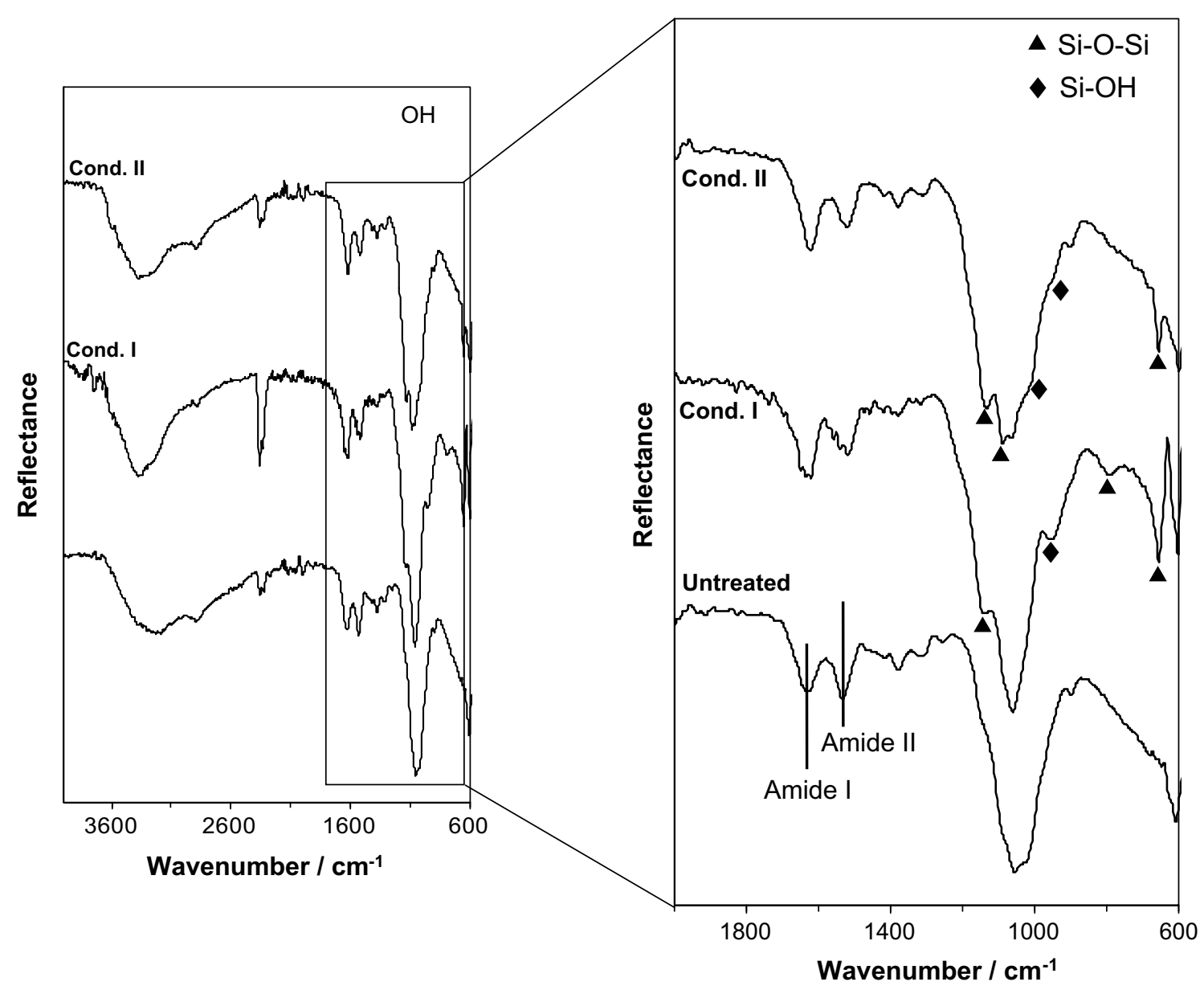

Fig. 3. FTIR spectra of the surfaces of chitosan microparticles treated with a calcium silicate solution under condition I or II.

Table 1

Atomic concentrations and corresponding atomic ratios (calculated from XPS spectra) of chitosan microparticles before and after treatment with a calcium silicate solution under condition I ( $12 \mathrm{~h}$ of immersion) or II ( $1 \mathrm{~h}$ of immersion in the solution that has aged for $24 \mathrm{~h}$ before using)

\begin{tabular}{|c|c|c|c|c|c|c|c|}
\hline \multirow[t]{2}{*}{ Material } & \multicolumn{6}{|c|}{ Atomic concentration $(\%)$} & \multirow{2}{*}{$\begin{array}{l}\mathrm{C} / \mathrm{Si} \\
\text { ratio }\end{array}$} \\
\hline & $\mathrm{C}_{1 \mathrm{~s}}$ & $\mathrm{O}_{1 \mathrm{~s}}$ & $\mathrm{~N}_{1 \mathrm{~s}}$ & $\mathrm{~S}_{2 \mathrm{p}}$ & $\mathrm{Si}_{2 \mathrm{p}}$ & $\mathrm{Ca}_{2 \mathrm{p}}$ & \\
\hline $\begin{array}{l}\text { Chitosan microparticles } \\
\text { (untreated) }\end{array}$ & 68.3 & 26.2 & 3.5 & 1.9 & - & - & - \\
\hline Condition I & 27.9 & 44.0 & 1.2 & 5.4 & 16.3 & 3.6 & 1.7 \\
\hline Condition II & 26.1 & 46.8 & 1.1 & 4.7 & 17.4 & 3.0 & 1.5 \\
\hline
\end{tabular}

tion peaks appeared, namely, $39.82^{\circ}$ and $46.71^{\circ}$ in $2 \theta$, corresponding to (310) and (222) diffraction planes of apatite (see Fig. $5 b$ ).

Figs. 6 and 7 show FE-SEM images and EDS spectra of the surface of microparticles, untreated and treated with calcium silicate solution under conditions I and II, then soaked in SBF for 1, 3 and 7 days. After the soaking in the calcium silicate solution, tiny needle-like crystals were formed on the surface of the microparticles. This surface structural change was brought about by modification with calcium silicate. When the chitosan microparticles treated with a calcium silicate solution under condition I were soaked in SBF for up to 7 days, the microparticles were completely covered with a uniform and dense apatite layer (see Fig. 6a), which is in agreement with the TF-XRD patterns in Fig. 5a. After 1 day, only the formation of calcium phosphate nuclei was observed; these nuclei increased in both number and size with increasing soaking time in SBF, and coalesced to form an apatite layer after 7 days.

For condition II, the chitosan microparticles showed the ability to induce the formation of an apatite layer within only 1 day in SBF (see Fig. 6b). This layer became more dense and compact with increasing soaking time in SBF. Moreover, at higher magnifications, we observed a finer structure where needle-like crystals were agglomerated.

By EDS measurement, the presence of elemental sulfur (S) was detected on the surface of untreated chitosan microparticles, which came from the stabilization reagent of the chitosan microparticles (see Fig. 7). After the calcium silicate treatment under conditions I and II, appreciable quantities of silicon $(\mathrm{Si}), \mathrm{S}$, chlorine $(\mathrm{Cl})$ and calcium $(\mathrm{Ca})$ were detected on the surface of the chitosan microparticles (see Fig. 7a and b), which is in good agreement with the detection of calcium sulphate $\left(\mathrm{CaSO}_{4} \cdot 0.5 \mathrm{H}_{2} \mathrm{O}\right)$ in the TF-XRD patterns in Fig. 5. 

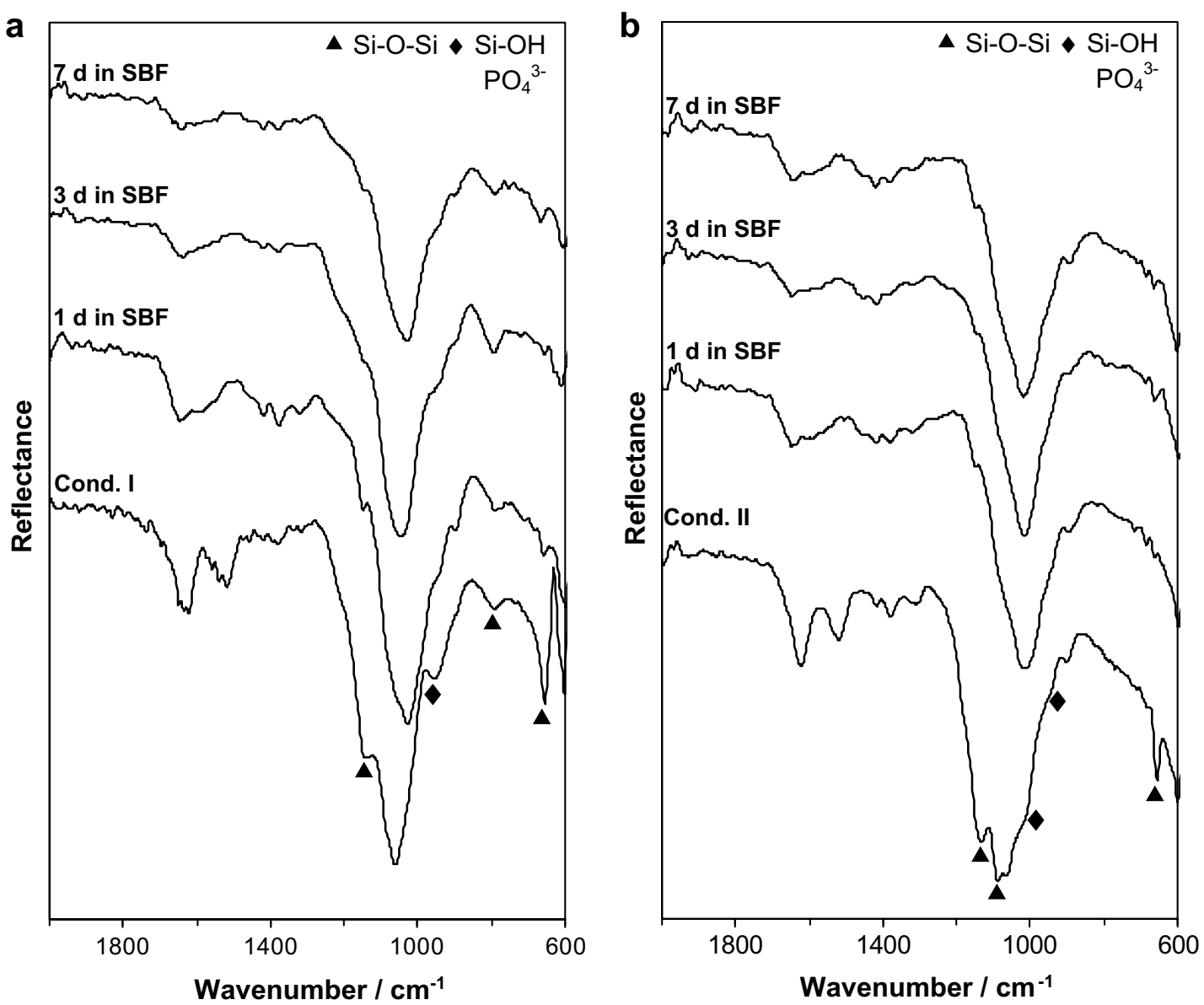

Fig. 4. FTIR spectra of the surfaces of chitosan microparticles treated with a calcium silicate solution under condition I or II and subsequently soaked in SBF for 1,3 and 7 days.

The peak intensities of $\mathrm{Ca}$ and $\mathrm{Si}$ under condition I were higher and lower, respectively, than under condition II. Also, the peak intensity of $\mathrm{Cl}$ under condition I was higher than under condition II. After soaking in SBF for 7 days, strong peaks ascribed to $\mathrm{Ca}$ and phosphorus $(\mathrm{P})$ were detected (see Fig. 7a). When the microparticles were treated with a calcium silicate solution under condition II, a significant quantity of $\mathrm{Ca}$ and $\mathrm{P}$ was detected after only 1 day in SBF (see Fig. 7b). The intensity of $\mathrm{Ca}$ and $\mathrm{P}$ peaks increased significantly with increasing soaking time in SBF. These results are in good agreement with those obtained from the TF-XRD analysis in Fig. 5b.

Fig. 8 shows the changes in calcium, phosphorus and silicon concentrations of SBF in which chitosan microparticles treated with a calcium silicate solution under condition I or II were soaked for various periods up to 7 days.

For both conditions I and II, the calcium concentration increased in the initial $24 \mathrm{~h}$ in SBF due to the release of calcium ions from the surface of the specimen into SBF, although this increase was higher for condition I than for condition II. As for the phosphorus concentration, there was a remarkable decrease with increasing soaking time. This decrease was more pronounced for condition I. Fur- thermore, an appreciable increase in silicon concentration was observed for both conditions. However, this increase was slightly accentuated for the microparticles treated with a calcium silicate solution under condition II. As the soaking time in SBF increase, a decrease in calcium and phosphorus concentrations was observed. On the other hand, no change was observed in the calcium and phosphorus concentrations for the untreated chitosan microparticles because, as mentioned above, chitosan does not have apatite-forming ability in SBF.

\section{Discussion}

Recently, much attention [8,9,39-50] has been focused on the use of natural origin polymers, like polysaccharides, such as starch, chitin and chitosan, and others, such as soy proteins and casein, because they are widely available in nature, cost-effective, biodegradable and non-toxic. Furthermore, chitosan has recently drawn considerable interest due to its favourable biological properties over other polymers $[5,6,8-10,25,51,52]$. Therefore, it is a polymer that exhibits many interesting properties, such as low toxicity, biocompatibility and biodegradability [5,6,8-10,51,52]. The most important feature of chitosan is its hydrophilicity 

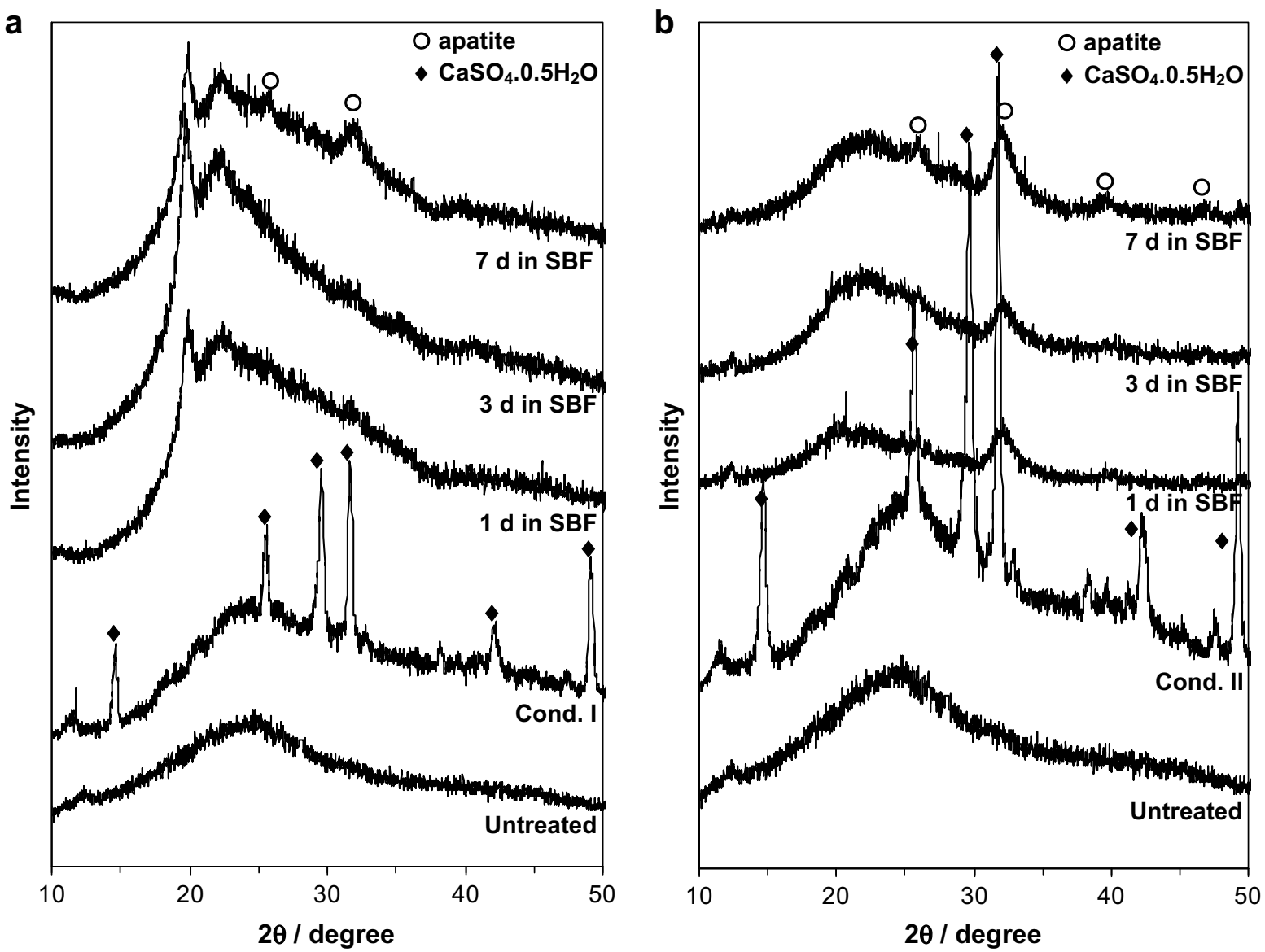

Fig. 5. TF-XRD patterns of the surfaces of chitosan microparticles treated with a calcium silicate solution under condition I or II and subsequently soaked in SBF for 1,3 and 7 days.
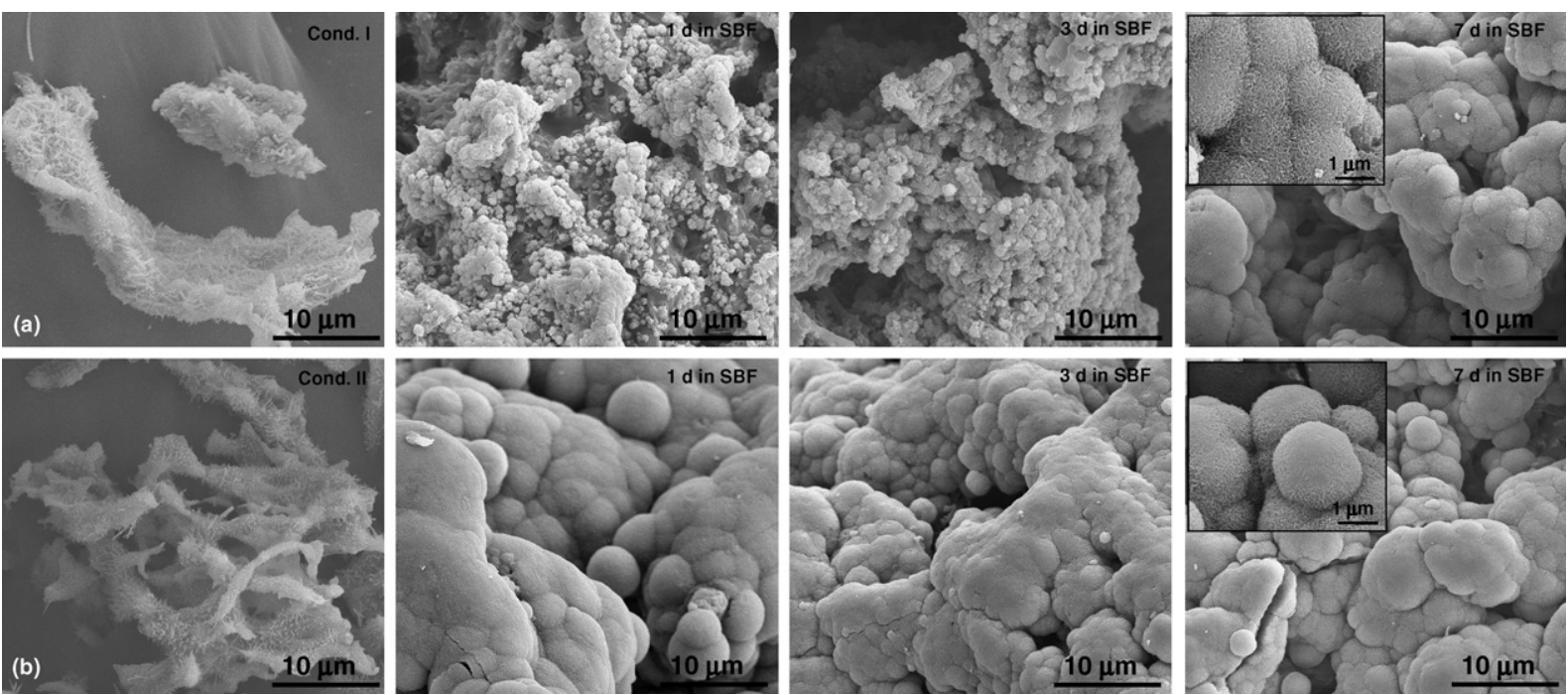

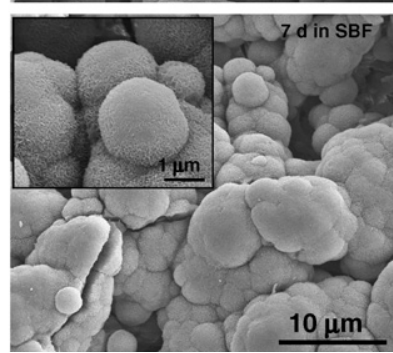

Fig. 6. SEM photographs of the surface of chitosan microparticles treated with a calcium silicate solution under condition I or II and subsequently soaked in SBF for 1, 3 and 7 days.

and its high content of primary amino groups, which make this polymer rather unique. However, the presence of these groups does not confer a bioactivity character to the chitosan, which limits its use for bone related applications.
These statements are in agreement with the results of Tanahashi et al. [53], who found that these groups have quite a weak apatite nucleating ability, i.e. they require soaking in SBF for a period longer than 7 days. 

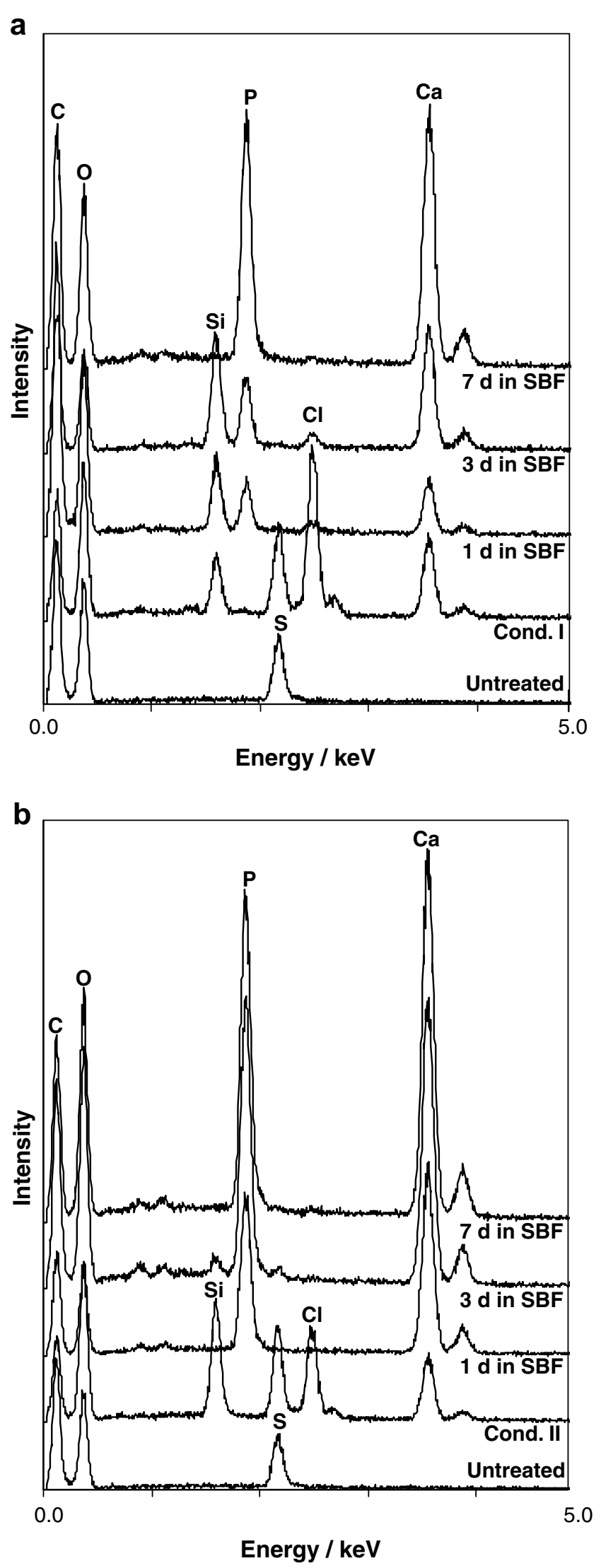

Fig. 7. EDS profiles of the surface of chitosan microparticles, which were treated with a calcium silicate solution under condition I or II and subsequently soaked in SBF for 1, 3 and 7 days.
In this study, when chitosan microparticles were soaked in a calcium silicate solution, $\mathrm{Si}-\mathrm{OH}$ groups formed on their surface, and these have the ability to induce the formation of an apatite layer. Such a novel system can be used as an injectable bone substitute, although the mechanical properties are not ideal. To over knowledge, such a type of coating method has never been used on chitosan.

As shown in Fig. 2, in the present study, we used the freeze-dried chitosan microparticles with irregular shapes. For injectable biomaterials, a spherical shape is more advantageous as their geometry allows them to be delivered more easily through needles. For that reason, the optimization of freeze-drying of chitosan microparticles will be investigated further with the use of cryoprotective agents to prevent aggregation and preserve the spherical morphology during drying.

As shown in Figs. 5 and 6, the microparticles treated with calcium silicate solution under conditions I and II formed apatite on their surfaces within 7 days and 1 day in $\mathrm{SBF}$, respectively. The number of $\mathrm{Si}-\mathrm{OH}$ groups, effective in inducing apatite nucleation $[27,29,54-56]$, on the microparticles before soaking in SBF was different between the two conditions (see Fig. 3). These differences might be attributed to the further progress of hydrolysis and polycondensation of TEOS in the calcium silicate solution due to an aging period, such as the $24 \mathrm{~h}$ in condition II. Such an aging period leads to an increase in the oxygen and silicon contents on the surface of the chitosan microparticles, which is in agreement with the XPS results; the $\mathrm{C} / \mathrm{Si}$ ratio was also higher for condition II than for condition I (see Table 1). Therefore, the chitosan microparticles under condition II had more $\mathrm{Si}-\mathrm{OH}$ available for the induction of an apatite coating. The hydrolysis and polycondensation of TEOS in the calcium silicate solution was not fully completed for condition I. In addition, these results are in agreement with those obtained from FTIR measurement (see Fig. 3), since the presence of $\mathrm{Si}-\mathrm{O}-\mathrm{Si}$ and $\mathrm{Si}-\mathrm{OH}$ bands as well as their intensities were stronger for the calcium silicate treatment under condition II than under condition I. Moreover, the chitosan microparticles were soaked in the calcium silicate solution for $12 \mathrm{~h}$ under condition I. Such a long soaking time in the calcium silicate solution only caused the adsorption of a large amount of $\mathrm{Si}, \mathrm{Ca}$ and $\mathrm{Cl}$ on the chitosan surface due to the higher hydrophilicity of chitosan, as shown in Fig. 7a.

From the ICP results showed in Fig. 8, when the chitosan microparticles were treated with calcium silicate solution under condition I, they showed the largest calcium concentration increase in the initial $24 \mathrm{~h}$ in SBF solution. This might be because chitosan has the water-uptake properties to allow the adsorption of a large amount of calcium ions from the calcium silicate solution, and hence the microparticles released a fairly large amount of calcium ions into the SBF during soaking. Also, an accentuated decrease of the phosphorus concentration was observed, which may be due to the interaction between the amino groups in the chitosan structure and the phosphate ions 

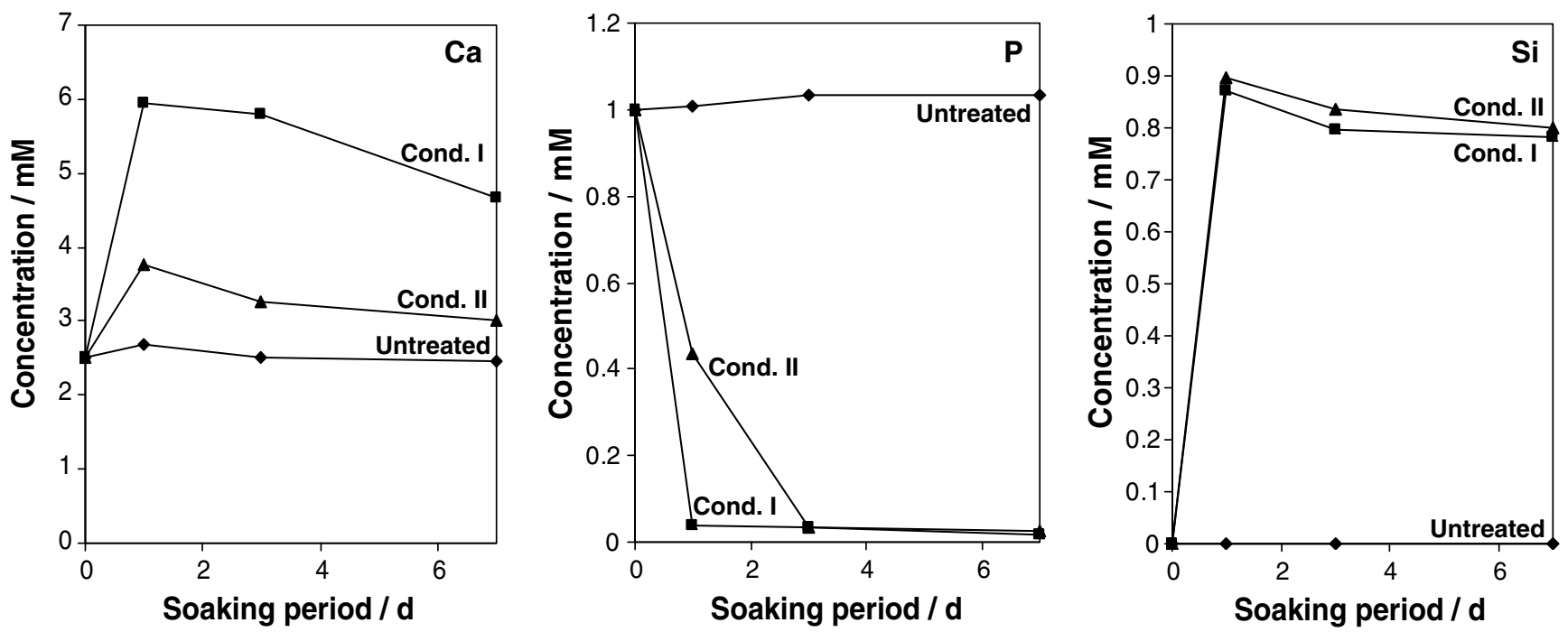

Fig. 8. Changes in $\mathrm{Ca}, \mathrm{P}$ and $\mathrm{Si}$ concentrations of SBF in which chitosan microparticles were treated with a calcium silicate solution under condition I or II and subsequently soaked in SBF for 1, 3 and 7 days.

present in the SBF solution. On the other hand, such a decrease is related with apatite formation. For condition II, only a small increase in the calcium concentration was observed during the initial $24 \mathrm{~h}$ in SBF, since the chitosan microparticles consumed the released calcium ions to form apatite on their surfaces within 1 day. The release of silicon was slightly higher under condition II than under condition I, which means that the calcium silicate layer formed under condition II dissolved into SBF more rapidly than under condition I. The release of silicon is attributed to the dissolution of silicon ions from the calcium silicate layer, which results in the formation of the $\mathrm{Si}-\mathrm{OH}$ groups that are responsible for the apatite nucleation.

These results indicate that the amount of $\mathrm{Si}-\mathrm{OH}$ groups can be speculated by two parameters: the rate of the dissolution of the silica into the SBF, because the dissolution of the silica gel, in this case calcium silicate gel, proceeds via the hydrolysis of silica [27,28]; and the aging period of the calcium silicate solution. Since the aging period in the calcium silicate solution under condition II was $24 \mathrm{~h}$, it led to better hydrolysis and polycondensation of TEOS in the calcium silicate solution. Furthermore, the soaking time of only $60 \mathrm{~min}$ in this solution was enough to produce a relatively high density of $\mathrm{Si}-\mathrm{OH}$ on the chitosan microparticles surface, which is a prerequisite for apatite formation in the body environment. These results are in agreement with the FTIR, XPS and EDS analyses (see Table 1 and Figs. 3 and $7 \mathrm{~b}$ ).

When the calcium silicate-coated microparticles were soaked in $\mathrm{SBF}$, the calcium ions in the calcium silicate layer were released into the SBF to form many $\mathrm{Si}-\mathrm{OH}$ groups and simultaneously increased the ionic activity product of the surrounding fluid with respect to apatite. The $\mathrm{Si}-\mathrm{OH}$ groups induce apatite nucleation, and the increased ionic activity product accelerates the nucleation rate of apatite. Once apatite nuclei are formed, they can grow into a uni- form layer by consuming the calcium and phosphate ions from the SBF, since the SBF is already highly supersaturated with respect to apatite [57]. This is supported by the results obtained by the measurements of calcium and phosphorus concentrations of SBF shown in Fig. 8. On the other hand, in terms of chemical bonding between $\mathrm{Si}-$ $\mathrm{OH}$ and apatite, we can speculate that the $\mathrm{Si}-\mathrm{OH}$ group may have a negative charge $\left(\mathrm{Si}_{-} \mathrm{O}^{-}\right)$in the $\mathrm{SBF}$ according

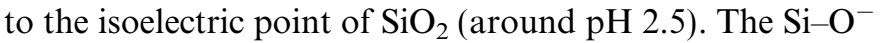
formed may interact with positively charged $\mathrm{Ca}^{2+}$ ions to form a Ca-rich positive thin layer, and finally combine with negatively charged $\mathrm{PO}_{4}^{3-}$ ions to form amorphous calcium phosphate, which transforms into apatite in SBF [58]. Therefore, we can speculate that some chemical bonding such as $\mathrm{Si}-\mathrm{O}-\mathrm{Ca}-\mathrm{O}-\mathrm{Si}$ exists at the interface between apatite and calcium silicate.

By incorporating $\mathrm{Si}-\mathrm{OH}$ groups into the chitosan microparticles, it is thus possible to have a biodegradable material with bone-bonding properties, which can therefore promote healing at a faster rate, leading to the unique strength of such interfaces. This material would ultimately enhance the repair/regeneration several-fold, and ultimately improve patient compliance and comfort. The development of such material has several advantages compared with other systems [30-32], including water-uptake and swelling properties, its easily application during surgery, flexibility to fill various types of bone defect sites with closer packing, which provides a good osteointegration, and also the biodegradability of these microparticles, which is a further advantage as no surgical removal of the implant is needed. Such properties make this material suitable for bone substitutes in the orthopaedic field. Moreover, due to the cationic nature of chitosan and predictable degradation rate, these microparticles can also have the potential to incorporate a therapeutic agent and release them in a controlled fashion. Therefore, the combination of the biodeg- 
radation and osteoconduction properties of these microparticles with the possible release of a bioactive agent make it promising as an injectable bone substitute and at same time a controlled release drug delivery system [59].

\section{Conclusions}

The growth of a bonelike apatite layer on chitosan microparticles after a calcium silicate treatment was successfully achieved in SBF within 1 day. Moreover, it was shown that the incorporation of $\mathrm{Si}-\mathrm{OH}$ groups and the water-uptake properties of chitosan, which allow it to absorb calcium ions from the calcium silicate solution by the present method, give it the ability to induce the formation of an apatite layer. In this sense, these biodegradable microparticles maximize the osteoconductive behaviour with the presence of $\mathrm{Si}-\mathrm{OH}$ groups, which allow bone ingrowth into the implant to occur as the microparticles are resorbed with time. The use of degradable polymers as microparticles forms a major approach in the development of bone substitutes when compared to the nondegradable systems. Therefore, combining all the properties of these chitosan microparticles - biodegradability, osteoconductivity and mouldablity - it is possible to have an injectable biomaterial system that can also act as a drug delivery system.

\section{Acknowledgments}

I.B.L. thanks the Portuguese Foundation for Science and Technology (FCT), for providing her a PhD scholarship (SFRH/BD/9031/2002), the European Union funded STREP Project HIPPOCRATES (NMP3-CT-2003505758) and the European NoE EXPERTISSUES (NMP3-CT-2004-500283).

\section{References}

[1] Calvert P, Rieke P. Biomimetic mineralization in and on polymers. Chem Mater 1996;8(8):1715-27.

[2] Perren SM, Gogolewski. Clinical requirements for bioresorbable implants internal fixation. In: Kwok-sui L, Leung-Kim H, PingChung L, editors. Biodegradable implants in fracture fixation. Hong Kong: World Scientific; 1994. p. 35-43.

[3] Suh H. Recent advances in biomaterials. Yonsei Med J 1998;39(2):87-96.

[4] Temenoff JS, Mikos AG. Injectable biodegradable materials for orthopedic tissue engineering. Biomaterials 2000;21(23):2405-12.

[5] Di Martino A, Sittinger M, Risbud MV. Chitosan: a versatile biopolymer for orthopaedic tissue-engineering. Biomaterials 2005;26(30):5983-90.

[6] Kumar G, Bristow JF, Smith PJ, Payne GF. Enzymatic gelation of the natural polymer chitosan. Polymer 2000;41(6):2157-68.

[7] Kumar MNVR, Muzzarelli RAA, Muzzarelli C, Sashiwa H, Domb AJ. Chitosan Chemistry and Pharmaceutical Perspectives. Chem Rev 2004; 104:6017-84.

[8] Oliveira JM, Rodrigues MT, Silva SS, Malafaya PB, Gomes ME, Viegas CA, et al. Novel hydroxyapatite/chitosan bilayered scaffold for osteochondral tissue-engineering applications: Scaffold design and its performance when seeded with goat bone marrow stromal cells. Biomaterials 2006;27(36):6123-37.
[9] Tuzlakoglu K, Alves CM, Mano JF, Reis RL. Production and characterization of chitosan fibers and 3-D fiber mesh scaffolds for tissue engineering applications. Macromol Biosci 2004;4(8):811-9.

[10] Zhao F, Grayson WL, Ma T, Bunnell B, Lu WW. Effects of hydroxyapatite in 3-D chitosan-gelatin polymer network on human mesenchymal stem cell construct development. Biomaterials 2006;27(9):1859-67.

[11] Yamaguchi I, Tokuchi K, Fukuzaki H, Koyama Y, Takakuda K, Monma H, et al. Preparation and microstructure analysis of chitosan/ hydroxyapatite nanocomposites. J Biomed Mater Res 2001;55(1): $20-7$.

[12] Kim HM. Ceramic bioactivity and related biomimetic strategy. Curr Opin Solid State Mater Sci 2003;7(4-5):289-99.

[13] Ohgushi H, Caplan AI. Stem cell technology and bioceramics: from cell to gene engineering. J Biomed Mater Res 1999;48(6):913-27.

[14] Aoki H. Science and medical applications of hydroxyapatite. Tokyo: Takayama Press System Centre Co. Inc.; 1991.

[15] Posner AS. The mineral of bone. Clin Orthop Relat Res 1985;200:87-99.

[16] Hench LL. Biomaterials: a forecast for the future. Biomaterials 1998;19(16):1419-23.

[17] Gross KA, Berndt CC. Thermal processing of hydroxyapatite for coating production. J Biomed Mater Res 1998;39(4):580-7.

[18] Daculsi G. Biphasic calcium phosphate concept applied to artificial bone, implant coating and injectable bone substitute. Biomaterials 1998;19(16):1473-8.

[19] Davies JE, Baldan N. Scanning electron microscopy of the bonebioactive implant interface. J Biomed Mater Res 1997;36(4):429-40.

[20] Hench LL, Splinter RJ, Allen WC, Greenlee TK. Bonding mechanisms at the interface of ceramic prosthetic materials. J Biomed Mater Res Symp 1971;2:117-41.

[21] Neo M, Kotani S, Fujita Y, Nakamura T, Yamamuro T, Bando Y, et al. Differences in ceramic-bone interface between surface-active ceramics and resorbable ceramics: a study by scanning and transmission electron microscopy. J Biomed Mater Res 1992;26(2):255-67.

[22] Neo M, Kotani S, Nakamura T, Yamamuro T, Ohtsuki C, Kokubo T. A comparative study of ultrastructures of the interfaces between four kinds of surfaceactive ceramic and bone. J Biomed Mater Res 1992;26(11):1419-32.

[23] Neo M, Nakamura T, Ohtsuki C, Kokubo T, Yamamuro T. Apatite formation on three kinds of bioactive material at an early stage in vivo: a comparative study by transmission electron microscopy. J Biomed Mater Res 1993;27(8):999-1006.

[24] Kokubo T, Kim HM, Kawashita M. Novel bioactive materials with different mechanical properties. Biomaterials 2003;24(13):2161-75.

[25] Tuzlakoglu K, Reis RL. Formation of bone-like apatite layer on chitosan fiber mesh scaffolds by a biomimetic spraying process. J Mater Sci: Mater Med 2007;18(7):1279-86.

[26] Kokubo T, Kushitani H, Sakka S, Kitsugi T, Yamamuro T. Solutions able to reproduce in vivo surface-structure changes in bioactive glassceramic A-W. J Biomed Mater Res 1990;24(6):721-34.

[27] Li P, Ohtsuki C, Kokubo T, Nakanishi K, Soga N, Nakamura T, et al. Process of Formation of Bone-Like Apatite Layer on Silica-Gel. J Mater Sci: Mater Med 1993;4(2):127-31.

[28] Li P, Ye X, Kangasniemi I, de Blieck-Hogervorst JM, Klein CP, de Groot K. In vivo calcium phosphate formation induced by sol-gelprepared silica. J Biomed Mater Res 1995;29(3):325-8.

[29] Li PJ, Ohtsuki C, Kokubo T, Nakanishi K, Soga N, Nakamura T, et al. Apatite Formation Induced by Silica-Gel in a Simulated BodyFluid. J Am Ceram Soc 1992;75(8):2094-7.

[30] Ragel CV, Vallet-Regi M. In vitro bioactivity and gentamicin release from glasspolymer- antibiotic composites. J Biomed Mater Res 2000;51(3):424-9.

[31] Sivakumar M, Manjubala I, Rao KP. Preparation, characterization and in-vitro release of gentamicin from coralline hydroxyapatitechitosan composite microspheres. Carbohydr Polym 2002;49(3):281-8.

[32] Sivakumar M, Panduranga Rao K. Preparation, characterization and in vitro release of gentamicin from coralline hydroxyapatite-gelatin composite microspheres. Biomaterials 2002;23(15):3175-81. 
[33] Berthold A, Cremer K, Kreuter J. Preparation and characterization of chitosan microspheres as drug carrier for prednisolone sodium phosphate as model for antiinflammatory drugs. J Control Release 1996;39(1):17-25.

[34] Schaffazick SR, Pohlmann AR, Dalla-Costa T, Guterres SS. Freezedrying polymeric colloidal suspensions: nanocapsules, nanospheres and nanodispersion. A comparative study. Eur J Pharm Biopharm 2003;56(3):501-5.

[35] Morita T, Horikiri Y, Suzuki T, Yoshino H. Preparation of gelatin microparticles by co-lyophilization with poly(ethylene glycol): characterization and application to entrapment into biodegradable microspheres. Int J Pharm 2001;219(1-2):127-37.

[36] Bertoluzza A, Fagnano C, Morelli MA, Gottardi V, Guglielmi M. Raman and Infrared-Spectra on Silica-Gel Evolving toward Glass. J Non-Cryst Solids 1982;48(1):117-28.

[37] Pawlak A, Mucha A. Thermogravimetric and FTIR studies of chitosan blends. Thermochim Acta 2003;396(1-2):153-66.

[38] Koutsopoulos S. Synthesis and characterization of hydroxyapatite crystals: a review study on the analytical methods. J Biomed Mater Res 2002;62(4):600-12.

[39] Gomes ME, Godinho JS, Tchalamov D, Cunha AM, Reis RL. Alternative tissue engineering scaffolds based on starch: processing methodologies, morphology, degradation and mechanical properties. Mater Sci Eng C: Biomimet Supramol Syst 2002;20(1-2):19-26.

[40] Gomes ME, Holtorf HL, Reis RL, Mikos AG. Influence of the porosity of starchbased fiber mesh scaffolds on the proliferation and osteogenic differentiation of bone marrow stromal cells cultured in a flow perfusion bioreactor. Tissue Eng 2006;12(4):801-9.

[41] Gomes ME, Malafaya PB, Reis RL. Methodologies for processing biodegradable and natural origin scaffolds for bone and cartilage tissue-engineering applications. Method Mol Biol 2004;238:65-76.

[42] Gomes ME, Reis RL. Tissue engineering: key elements and some trends. Macromol Biosci 2004;4(8):737-42.

[43] Malafaya PB, Stappers F, Reis RL. Starch-based microspheres produced by emulsion crosslinking with a potential media dependent responsive behavior to be used as drug delivery carriers. J Mater Sci Mater Med 2006;17(4):371-7.

[44] Mano JF, Koniarova D, Reis RL. Thermal properties of thermoplastic starch/synthetic polymer blends with potential biomedical applicability. J Mater Sci Mater Med 2003;14(2):127-35.

[45] Mano JF, Sousa RA, Boesel LF, Neves NM, Reis RL. Bioinert, biodegradable and injectable polymeric matrix composites for hard tissue replacement: state of the art and recent developments. Compos Sci Technol 2004;64(6):789.
[46] Salgado AJ, Coutinho OP, Reis RL. Novel starch-based scaffolds for bone tissue engineering: cytotoxicity, cell culture, and protein expression. Tissue Eng 2004;10(3-4):465-74.

[47] Salgado AJ, Coutinho OP, Reis RL. Bone tissue engineering: state of the art and future trends. Macromol Biosci 2004;4(8):743-65.

[48] Silva GA, Costa FJ, Coutinho OP, Radin S, Ducheyne P, Reis RL. Synthesis and evaluation of novel bioactive composite starch/bioactive glass microparticles. J Biomed Mater Res A 2004;70(3):442-9.

[49] Silva GA, Costa FJ, Neves NM, Reis RL. Microparticulate release systems based on natural origin materials. Adv Exp Med Biol 2004;553:283-300.

[50] Tuzlakoglu K, Bolgen N, Salgado AJ, Gomes ME, Piskin E, Reis RL. Nano- and micro-fiber combined scaffolds: a new architecture for bone tissue engineering. J Mater Sci Mater Med 2005;16(12):1099-104.

[51] Falini G, Fermani S. Chitin mineralization. Tissue Eng 2004;10(1-2):1-6.

[52] Muzzarelli R, Baldassarre V, Conti F, Ferrara P, Biagini G, Gazzanelli G, et al. Biological activity of chitosan: ultrastructural study. Biomaterials 1988;9(3):247-52.

[53] Tanahashi M, Matsuda T. Surface functional group dependence on apatite formation on self-assembled monolayers in a simulated body fluid. J Biomed Mater Res 1997;34(3):305-15.

[54] Cho SB, Kokubo T, Nakanishi K, Soga N, Ohtsuki C, Nakamura T, et al. Dependence of apatite formation on silica gel on its structure: effect of heat treatment. J Am Ceram Soc 1995;78(7):1769-74.

[55] Cho SB, Nakanishi K, Kokubo T, Soga N, Ohtsuki C, Nakamura T. Apatite formation on silica gel in simulated body fluid: its dependence on structures of silica gels prepared in different media. J Biomed Mater Res 1996;33(3):145-51.

[56] Li P, Nakanishi K, Kokubo T, de Groot K. Induction and morphology of hydroxyapatite, precipitated from metastable simulated body fluids on sol-gel prepared silica. Biomaterials 1993;14(13):963-8.

[57] Kim H-M. Bioactive ceramics: challenges and perspectives. J Ceram Soc Jpn 2001;109:S49-57.

[58] Takadama H, Kim HM, Kokubo T, Nakamura T. X-ray photoelectron spectroscopy study on the process of apatite formation on a sodium silicate glass in simulated body fluid. J Am Ceram Soc 2002;85(8):1933-6.

[59] Iooss P, Le Ray AM, Grimandi G, Daculsi G, Merle C. A new injectable bone substitute combining poly(epsilon-caprolactone) microparticles with biphasic calcium phosphate granules. Biomaterials 2001;22(20):2785-94 